PharmacoEconomics \& Outcomes News 866, p34 - 14 Nov 2020

\title{
NICE consulting on methods used for health technology evaluation
}

The UK National Institute for Health and Care Excellence (NICE) has initiated public consultation on proposals for changing its methods and processes used for evaluating and developing guidance on health technologies.

"As we develop a new regulatory and access environment for medicines, medical devices, diagnostics and digital health technologies, our methods should be aimed at supporting early patient access at a reasonable cost to the NHS, for example by encouraging companies to launch their products in the UK first," commented Meindert Boysen, director of the Centre for Health Technology Evaluation at NICE. "Ensuring that our methods are clear, transparent and predictable should allow us to speed up evaluation processes for new and emerging technologies. This is particularly important in our response to COVID-19, but also allows us to further consider how to best evaluate the value of specific new technologies such as cell and gene therapies," he said.

On 24 November 2020, NICE will host an online consultation event. Those who wish to participate should submit questions in advance when registering for the event. Speakers at the event will include: Meindert Boysen; Stephanie Callaghan, project manager; Helen Knight, programme director at Centre for Health Technology Evaluation; Lizzie Thomas, senior public involvement adviser; and Ian Watson, senior technical adviser.

The consultation period will close on 18 December 2020.

NICE. NICE's methods of technology evaluation - presenting a case for change. Internet Document : 6 Nov 2020. Available from: URL: https://www.nice.org.uk/news/article/ nice-s-methods-of-technology-evaluation-presenting-a-case-for-change 